\title{
Time Course of Extracellular Dopamine and Behavioral Sensitization to Cocaine. I. Dopamine Axon Terminals
}

\author{
Peter W. Kalivas and Patricia Duffy \\ Alcohol and Drug Abuse Program and Department of Veterinary Comparative Anatomy, Pharmacology and Physiology, \\ Washington State University, Pullman, Washington 99164-6520
}

\begin{abstract}
Repeated administration of cocaine to rodents produces a progressive augmentation in motor activity known as behavioral sensitization. By using microdialysis in the ventral striatum, some studies have found that the development of behavioral sensitization is associated with a similar augmentation in dopamine release, while others have not. It was postulated that differences in doses and withdrawal periods may account for the discrepancies between studies. Rats were behaviorally sensitized to daily peripheral injections using two cocaine treatment regimens $(15 \mathrm{mg} / \mathrm{kg}$, i.p. $\times 5$ d or $30 \mathrm{mg} / \mathrm{kg}$, i.p. $\times 5 \mathrm{~d})$. Using in vivo microdialysis in the ventral striatum, the effect of acute cocaine $(15 \mathrm{mg} / \mathrm{kg}$, i.p.) on extracellular dopamine content and motor behavior was examined at various times after discontinuing daily treatments. Twenty-four hours after discontinuing the low dose of daily cocaine, the increase in motor activity and extracellular dopamine elicited by an acute cocaine challenge was significantly elevated. In contrast, following the higher daily treatment regimen there was a significant augmentation in motor activity, but the increase in extracellular dopamine produced by cocaine was significantly reduced. When rats were challenged 10-14 d after discontinuing either dosage regimen of daily cocaine, the increase in both motor activity and extracellular dopamine was augmented. In general, the increase in extracellular dopamine by an acute cocaine challenge increased over time when rats were challenged between 1 and $22 \mathrm{~d}$ after discontinuing daily cocaine. Basal concentrations of extracellular dopamine were determined by measuring the in vivo flux of dopamine across the dialysis membrane, and there was no significant difference at $\mathbf{2 4} \mathrm{hr}$ or $\mathbf{2}$ weeks following the last daily injection of saline or cocaine. It is concluded that behavioral sensitization to cocaine is generally associated with an augmentation in extracellular dopamine in the ventral striatum, but that high doses of daily cocaine produce apparent tolerance to the augmentation in extracellular dopamine during the early withdrawal period.
\end{abstract}

[Key words: cocaine, dopamine, nucleus accumbens, sensitization, locomotion, dialysis]

\footnotetext{
Received Feb. 11, 1992; revised Apr. 28, 1992; accepted July 17, 1992.

We thank Jenny Baylon for assistance in preparing the manuscript. The research was supported in part by U.S. Public Health Service Grants DA-03906 and MH40817, and by Research Career Development Award DA-00158.

Correspondence should be addressed to Peter Kalivas, Ph.D., Department of VCAPP, Washington State University, Pullman, WA 99164-6520.

Copyright $\odot 1993$ Society for Neuroscience $0270-6474 / 93 / 130266-10 \$ 05.00 / 0$
}

The acute motor stimulant effect of systemic cocaine is thought to be mediated by increased dopamine transmission in the forebrain resulting from a blockade of presynaptic dopamine reuptake from the synaptic cleft (Hadfield and Nuggent, 1983; Reith et al., 1986; Izenwasser et al., 1990). Thus, cocaine-induced motor excitation is prevented by the microinjection of dopamine antagonists into the nucleus accumbens, or by destruction of accumbal dopamine terminals (van Rossum et al., 1962; Kelly and Iversen, 1975; Scheel-Kruger et al., 1977). Motor activity is also produced by direct cocaine administration into the nucleus accumbens (Delfs et al., 1990). Finally, the motor stimulation produced by acute peripheral cocaine injection is associated with an increase in extracellular dopamine in the ventral striatum, including the nucleus accumbens, as measured by in vivo dialysis (Di Chiara and Imperato, 1988; Hurd et al., 1989; Kalivas and Duffy, 1990; Pettit et al., 1990).

When cocaine is injected repeatedly, the motor stimulant response increases with each subsequent injection (Downs and Eddy, 1932; Post and Rose, 1976; Kalivas et al., 1988). This phenomenon, termed behavioral sensitization, has been shown to occur with as little as a single injection of cocaine (Weiss et al., 1989), and to persist for weeks after discontinuing cocaine treatment (Kalivas and Stewart, 1991). Like the acute motor stimulant effect of cocaine, the sensitized motor response has been postulated to result from augmented dopamine release in the forebrain. Because cocaine potentiates dopamine transmission by blocking the reuptake of dopamine into axon terminals, the use of traditional postmortem measures of dopamine turnover such as tissue levels of dopamine metabolites and dopa accumulation has not proven very useful in examining this hypothesis (Taylor and Ho, 1977; Hanson et al., 1987; Kalivas et al., 1988). More recently, in vivo brain microdialysis has been used to measure directly the extracellular concentration of dopamine in the nucleus accumbens and striatum. In general, this technique has verified the involvement of dopamine in behavioral sensitization to cocaine by showing that an increase in extracellular dopamine is associated with the augmented behavioral response to repeated cocaine injections (Akimoto et al., 1989; Kalivas and Duffy, 1990; Pettit et al., 1990). I Iowever, in one study where rats self-administered cocaine, there was a reduction, not an augmentation, in extracellular dopamine in the nucleus accumbens in response to an acute cocaine challenge (Hurd et al., 1989). Also, Segal and Kuczenski (1992b) recently observed that the daily administration of cocaine produced behavioral sensitization without augmenting the extracellular content of dopamine in the nucleus accumbens. Similar to cocaine, many dialysis studies conducted in amphetamine- or methamphetamine-sensitized rats reveal that augmented extracel- 
Table 1. Treatment groups for dialysis in the ventral striatum

\begin{tabular}{|c|c|c|c|c|c|c|}
\hline \multirow[b]{2}{*}{ Group } & \multicolumn{6}{|l|}{ Treatment day } \\
\hline & 1 & $2-6$ & 7 & 10 & $17-21$ & $27-29$ \\
\hline 1 & Saline (10) & Cocaine, $30 \mathrm{mg} / \mathrm{kg}$ & Saline (11) & - & Saline (13) & - \\
\hline 2 & Saline (7) & Saline & Cocaine (9) & - & Cocaine $(8)$ & - \\
\hline 3 & Cocaine (30) & Cocaine, $15 \mathrm{mg} / \mathrm{kg}$ & Cocaine (8) & Cocaine (8) & Cocaine (13) & Cocaine (9) \\
\hline 4 & Cocaine (22) & Cocaine, $30 \mathrm{mg} / \mathrm{kg}$ & Cocaine (12) & Cocaine (6) & Cocaine $(9)$ & Cocaine $(8)$ \\
\hline 5 & Saline & Saline & Basal (6) & - & Basal (6) & - \\
\hline 6 & Cocaine & Cocaine, $30 \mathrm{mg} / \mathrm{kg}$ & Basal (6) & - & Basal (8) & - \\
\hline
\end{tabular}

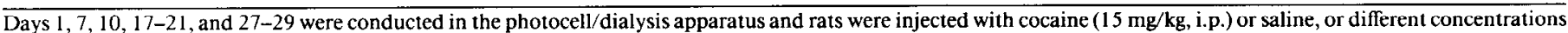

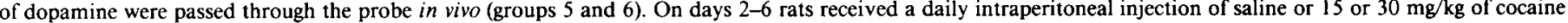
in the home cage. The number of determinations at each time is shown in parentheses.

lular dopamine levels in the nucleus accumbens and striatum are associated with behavioral sensitization (Robinson et al., 1988; Kazahaya et al., 1989; Akimoto et al., 1990; Patrick et al., 1991). However, one laboratory found that daily amphetamine administration resulted in robust behavioral sensitization without an accompanying augmentation in extracellular dopamine in the nucleus accumbens or striatum (Kuczenski and Segal, 1990; Segal and Kuczenski, 1992a).

One possible explanation for the negative reports is revealed in previous studies demonstrating that after longer drug withdrawal periods behavioral sensitization increases (Kolta et al., 1985; Robinson and Becker, 1986; Antelman, 1988). This seems especially true if large doses of psychostimulants are employed. The negative reports with microdialysis examined a relatively short withdrawal period of $24-48 \mathrm{hr}$, and in one of the cocaine studies, high doses of cocaine were being self-administered (approximately $30 \mathrm{mg} / \mathrm{kg}$, i.v. $\times 10 \mathrm{~d}$ ) (Hurd et al., 1989; Kuczenski and Segal, 1990; Segal and Kuczenski, 1992a,b). Based upon the possible role of withdrawal period and dose on the association between dopamine release and psychostimulant-induced behavioral sensitization, the following experiments examined the effect of two different daily doses of cocaine on extracellular dopamine in the nucleus accumbens and motor activity in response to a cocaine challenge made between 1 and $21 \mathrm{~d}$ after discontinuing daily drug treatment.

A small portion of these data were reported previously in a review (Kalivas and Stewart, 1991).

\section{Materials and Methods}

Animal housing and surgery. Male Sprague-Dawley rats (Laboratory Animal Resource Center, Pullman, WA) were individually housed with food and water made available ad libitum. A $12 \mathrm{hr} / 12 \mathrm{hr}$ light/dark cycle was used with the lights on at 6:30 hr. All injections of cocaine were made between 11:00 and 13:00 hr.

Rats weighing between 260 and $320 \mathrm{gm}$ were anesthetized with Equithesin $(3.0 \mathrm{ml} / \mathrm{kg} ; 9.7 \mathrm{gm}$ of sodium pentobarbital, $42.5 \mathrm{gm}$ of chloral hydrate, $21.3 \mathrm{gm}$ of $\mathrm{MgSO}_{4}$ dissolved in one liter of $11 \%$ ethanol, $42 \%$ propylene glycol, $\mathrm{v} / \mathrm{v}$ ) and mounted in a stereotaxic apparatus (David Kopf, Torrance, CA). Either chronic unilateral or bilateral dialysis (20 gauge stainless steel, $12 \mathrm{~mm}$ long) guide cannulas wcre implanted $3 \mathrm{~mm}$ dorsal to the nucleus accumbens $(\mathrm{A} / \mathrm{P} 8.7$ to $9.0 \mathrm{~mm}, \mathrm{D} / \mathrm{V}-0.5$ to 0.0 $\mathrm{mm}, \mathrm{M} / \mathrm{L} 1.7 \mathrm{~mm}$; relative to the interaural line according to the atlas of Pellegrino et al., 1979). The cannulas were cemented into place by affixing dental acrylic to three stainless steel screws tapped into the skull. The wounds were sutured, and the rats were allowed a minimum of 1 week recovery prior to beginning experimentation.

Microdialysis. All rats were placed into individual photocell cages (Omnitech Flectronic, Inc., Columbus, $\mathrm{OH}$ ) that had been modified to conduct intracranial dialysis experiments (Kalivas and Duffy, 1990). The dialysis probes were constructed as described by Robinson and Whishaw (1988), with $2.0-3.0 \mathrm{~mm}$ of active dialysis membrane exposed at the tip. The probes were inserted through one of the guide cannulas into the ventral striatum the night prior to the experiment. The next day, dialysis buffer $\left(5 \mathrm{~mm} \mathrm{KCl}, 120 \mathrm{~mm} \mathrm{NaCl}, 1.8 \mathrm{~mm} \mathrm{CaCl}_{2}, 1.2 \mathrm{~mm}\right.$ $\mathrm{MgCl}_{2}$, plus $0.2 \mathrm{~mm}$ phosphate-buffered saline to give a $\mathrm{pH}$ value of 7.4 and a final sodium concentration of $120.7 \mathrm{~mm}$ ) was advanced through the probe at a rate of $1.9 \mu \mathrm{l} / \mathrm{min}$ (Harvard Instruments, Boston, MA) for $2 \mathrm{hr}$. Baseline samples (20 min each) were collected for 60-80 min, and then cocaine $(15.0 \mathrm{mg} / \mathrm{kg}$, i.p.) or saline $(1.0 \mathrm{ml} / \mathrm{kg}$, i.p. $)$ was administered and between six and nine additional $20 \mathrm{~min}$ dialysis samples were obtained. Behavioral data were collected in $20 \mathrm{~min}$ intervals simultaneous with the dialysis samples. When the experiment was terminated, the dialysis probe was removed, and the animal returned to its home cage or killed for histological verification of dialysis probe placement (see below).

Treatment groups $1-4$. Table 1 shows the cocaine treatment and dialysis schedule. In the initial experiments, rats were implanted with a unilateral guide cannula $(N=22)$, and were examined at a single time point. However, in later experiments $(N=108)$, rats were implanted with bilateral guide cannulas and two experiments were performed in each rat. In all cases, each rat was acutely implanted with a dialysis probe only once in each guide cannula. Thus, rats receiving bilateral guide cannulas underwent two separate dialysis experiments (i.e., on days 1, 7, 10, 17-21, 27-29; see Table 1).

All rats were placed into the photocell/dialysis apparatus the night prior to day 1 and connected to a dialysis probe connector. However, only a portion of rats had a dialysis probe inserted into the ventral striatum $(N=69$ out of 130 rats). Daily injections on days $2-6$ were made in the home cage. All acute challenges of cocaine or saline made following the daily treatments (i.e., days 7-29) were in the photocell/ dialysis chamber, and the rats were attached to a dialysis connector with a dialysis probe inserted into the ventral striatum. In group 1, all rats were injected with saline $(1.0 \mathrm{ml} / \mathrm{kg}$, i.p. $)$ in the photocell $/$ dialysis apparatus on day 1 , and on days $2-6$ were given daily cocaine $(30 \mathrm{mg}$ $\mathrm{kg}$, i.p.) in the home cage. Then the rats were injected with saline $(1.0$ $\mathrm{ml} / \mathrm{kg}$, i.p.) in the photocell/dialysis chamber on days 7 and $/$ or 20 . The rats placed in group 2 were injected with saline on days $1-6$, and then challenged with cocaine $(15 \mathrm{mg} / \mathrm{kg}$, i.p.) on days 7 and $/$ or 20 . The treatments in group 3 consisted of cocaine $(15 \mathrm{mg} / \mathrm{kg}$, i.p.) on days $1-$ 6 followed by an acute cocaine challenge $(15 \mathrm{mg} / \mathrm{kg}$, i.p.) on days 7,10 , $17-21$, or $27-29$. The fourth treatment group received cocaine $(15 \mathrm{mg} /$ $\mathrm{kg}$, i.p.) on day 1 , cocaine $(30 \mathrm{mg} / \mathrm{kg}$, i.p. $)$ on days $2-6$, and an acute cocaine challenge $(15 \mathrm{mg} / \mathrm{kg}$, i.p.) on days $7,10,17-21$, or $27-29$. In 68 rats treated with the high dose of cocaine (i.e., groups 1 and 4), 9 died from convulsions occurring within $60 \mathrm{sec}$ after administering the cocaine. No convulsive activity was observed in the other rats. Of 238 possible dialysis experiments from 130 rats in groups $1-4,183(77 \%)$ were used in data analysis. In addition to cocainc-induced convulsions, experiments were excluded or not performed for one of the following reasons: probe placement was outside the ventral striatum, the guide cannula was obstructed, the acrylic implant was loose, the basal levels of dopamine were unstable, or chromatographic difficulties occurred.

Determination of basal levels of extracellular dopamine (groups 5 and 6). In separate animals, the basal concentration of extracellular dopamine was determined by adding dopamine to the dialysis perfusate at concentrations above and below the expected extracellular concentration to generate a series of points that were interpolated to measure the concentration at which no net flux of dopamine occurred across the dialysis membrane (Lonroth et al., 1987; Parsons and Justice, 1991; 

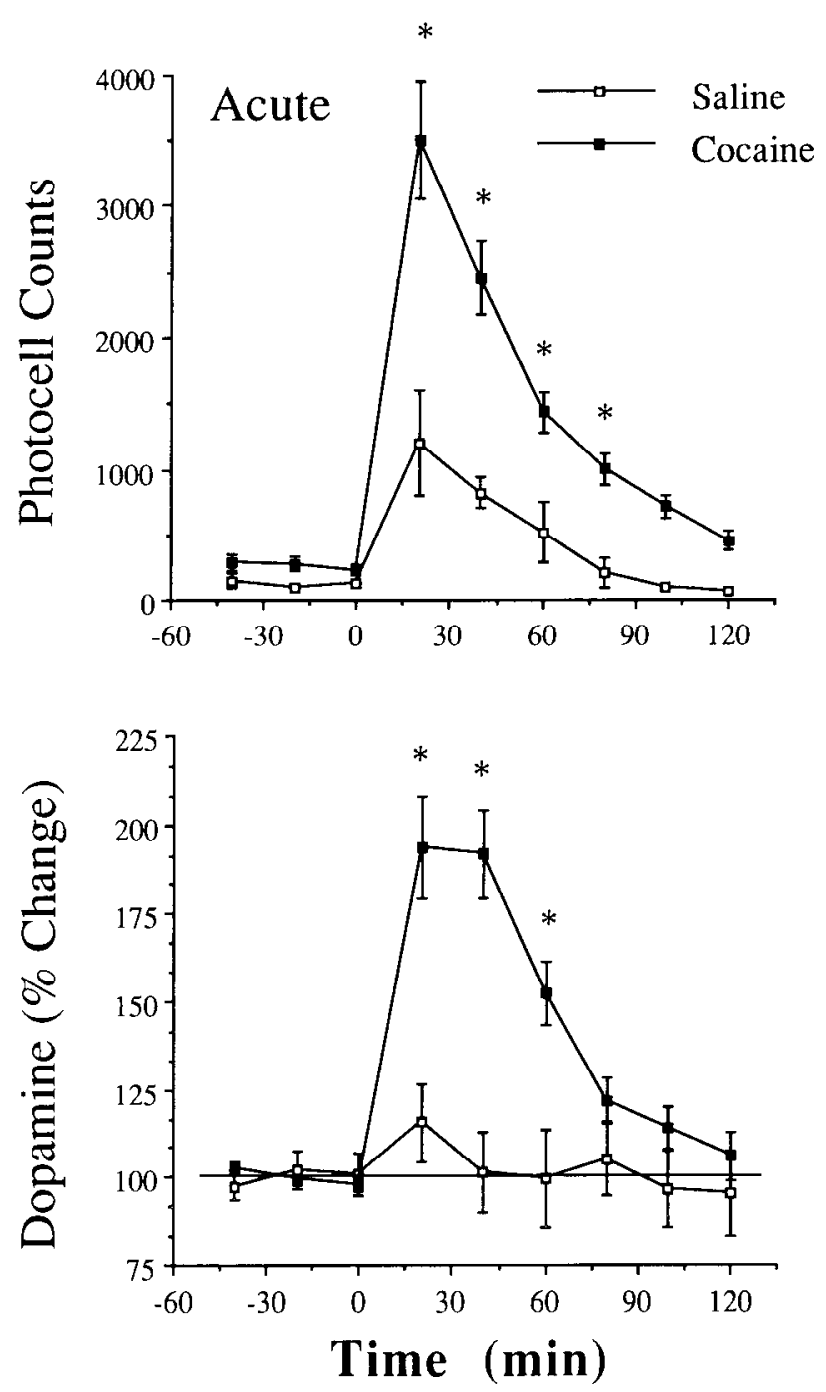

Figure 1. The effect of acute cocaine and saline in naive rats on motor activity and extracellular dopamine in the ventral striatum. Data were pooled from day 1 of treatment groups $1-4$. The neurochemical data were normalized by dividing all values by the average of the three baseline measurements made before the injection of acute saline. The data are shown as mean \pm SEM photocell counts or percentage change in dopamine. Basal values ( $\mathrm{fmol} / 20 \mathrm{~min}$ ) and number of determinations: saline, $62 \pm 8, N=17$; cocaine, $89 \pm 11, N=52(F=3.70, p=0.059)$. All data were analyzed using a two-way ANOVA with repeated measures over time. $F$ scores for the photocell counts: treatment $F=11.87, p<$ 0.001 ; time $F=46.51, p<0.001$; interaction $F=4.49, p<0.001$. Dopamine $F$ scores: treatment $F=6.13, p=0.016$; time $F=33.22, p$ $<0.001$; interaction $F=5.08, p<0.001 .^{*}, p<0.05$, comparing cocaine to saline using a least significant difference post hoc analysis, as described by Milliken and Johnson (1984).

Parsons et al., 1991a). A total of 18 rats with bilateral guide cannulas over the ventral striatum were used. As shown in Table 1, group 5 received saline $(1.0 \mathrm{ml} / \mathrm{kg}$, i.p.) on days $1-6$ and group 6 received cocaine $(15 \mathrm{mg} / \mathrm{kg}$, i.p.) on day 1 and cocaine $(30 \mathrm{mg} / \mathrm{kg}$, i.p.) on days $2-6$. The probes were inserted the night before the experiment. Perfusion of dialysis buffer (containing $0.25 \mathrm{~mm}$ ascorbic acid to inhibit dopamine oxidation) was begun in the morning, and $3 \mathrm{hr}$ later $0,1,3$, or $10 \mathrm{~nm}$ dopamine was advanced through the probe. Five $20 \mathrm{~min}$ dialysis samples were obtained at each concentration of dopamine, and the last two samples were averaged for a determination of the net flux of dopamine into or out of the dialysis buffer. A steady state between the perfusate and extracellular dopamine concentration was achieved more rapidly than has been reported previously (Parsons and Justice, 1991; Parsons et al., 1991 a) because of the nigher flow rate employed in the present study ( 1.9 vs. $0.2 \mu \mathrm{l} / \mathrm{min}$ ).
Measurement of dopamine in dialysis samples. The dialysis samples were collected into microfuge tubes in $20 \mu \mathrm{l}$ of mobile phase $(0.1 \mathrm{~m}$ citric acid, $75 \mathrm{mM} \mathrm{Na}_{2} \mathrm{HPO}_{4}, 0.6-1.0 \mathrm{~mm}$ heptane sulfonic acid, $0.1 \mathrm{~mm}$ EDTA, 13\% methanol, v/v, pH 3.8-4.2) plus $2.0 \mathrm{pmol}$ of dihydroxybenzylamine as the internal standard, and placed in a freezer $\left(-70^{\circ} \mathrm{C}\right)$ until analyzed for dopamine content. The samples were placed in a refrigerated autosampler (Gilson Medical Supplies, Middleton, WI) and dopamine content measured using HPLC with electrochemical detection. The dopamine was separated using a $25 \mathrm{~cm} \mathrm{C-18} \mathrm{reversed-phase}$ column (Bioanalytical Systems, West Lafayette, IN) and oxidized/reduced using coulometric detection (ESA Inc., Bedford, MA). Three electrodes were used: a preinjection port guard cell $(+0.4 \mathrm{~V})$ to oxidize the mobile phase, an oxidation analytical electrode $(+0.3 \mathrm{~V})$, and a reduction analytical electrode $(-0.2 \mathrm{~V})$. Peaks were recorded on a chart recorder and compared to an external standard curve (10-1000 fmol). For experiments using no net flux of dopamine, the $\mathrm{pH}$ of the mobile phase was 6.0 to avoid coelution of dopamine and ascorbic acid.

Histology and data analysis. Rats were killed with an overdose of pentobarbital, and their brains were removed and placed in $10 \%$ formalin for at least 1 week. The brains were then blocked and coronal sections $(100 \mu \mathrm{m}$ thick) made with a vibratome. The sections were mounted on gelatin-coated slides and stained with cresyl violet, and probe sites were determined by an individual unaware of the rats' behavioral or neurochemical response according to the atlas of Paxinos and Watson (1986).

Some rats were used twice while others only once (see above). To determine if the repeated measurements could be pooled with the single measurements, the variance between rats used twice and those used once was compared at each day with an $F$ test. In no instance was the $F$ score significant $(p<0.05)$, and the data were pooled. The neurochemical and behavioral time course data were statistically evaluated using a two-way analysis of variance (ANOVA) with repeated measures over time. The dopamine content was normalized to percentage change from the average of three baseline samples for each experiment prior to statistical analysis. Pos hoc evaluation of statistical differences was performed using a least significant difference test, as described by Milliken and Johnson (1984). To determine the concentration corresponding to no net flux of dopamine through the dialysis probe, regression analysis was performed (Lonroth et al., 1987; Parsons and Justice, 1991; Parsons et al., 1991), and basal concentrations compared between cocaine and saline treatment groups using a two-tailed Student's $t$ test.

\section{Results}

Effect of acute cocaine and saline in untreated rats. Figure 1 shows the pooled data from groups $1-4$ for animals undergoing dialysis on day 1 . The behavioral response to cocaine $(15 \mathrm{mg})$ $\mathrm{kg}$, i.p.) reached a maximum during the first $20 \mathrm{~min}$ after injection and returned to baseline levels by $100 \mathrm{~min}$ after injection. Cocaine significantly increased the level of extracellular dopamine in the ventral striatum, with a peak response between 20 and $40 \mathrm{~min}$ after injection, and returned to baseline levels by $80 \mathrm{~min}$ after injection.

Effect of daily cocaine on the response to a saline challenge, group 1. Figure 2 shows the behavioral and neurochemical effects of saline $(1.0 \mathrm{ml} / \mathrm{kg}$, i.p. $)$ in rats treated with daily cocaine $(30 \mathrm{mg} / \mathrm{kg}$, i.p. $\times 5 \mathrm{~d}$; group 1). This cocaine treatment regimen did not significantly alter the response to saline. A modest increase in horizontal photocell counts and no alteration in extracellular dopamine in the ventral striatum was produced on day 1 before daily cocaine administration and on days 7 and 20 after discontinuing the daily injections.

Effect of daily cocaine on the response to a cocaine challenge, groups 2-4. Figure 3 shows the effect of the three daily treatment regimens on extracellular dopamine and motor activity following an acute cocaine challenge ( $15 \mathrm{mg} / \mathrm{kg}$, i.p.) on day 7 (i.e., 24 $\mathrm{hr}$ after discontinuing daily treatments). Compared to the rats pretreated with daily saline (group 2), rats pretreated with daily cocaine demonstrated an increase in cocaine-induced motor activity. However, only at $20 \mathrm{~min}$ after cocaine administration 

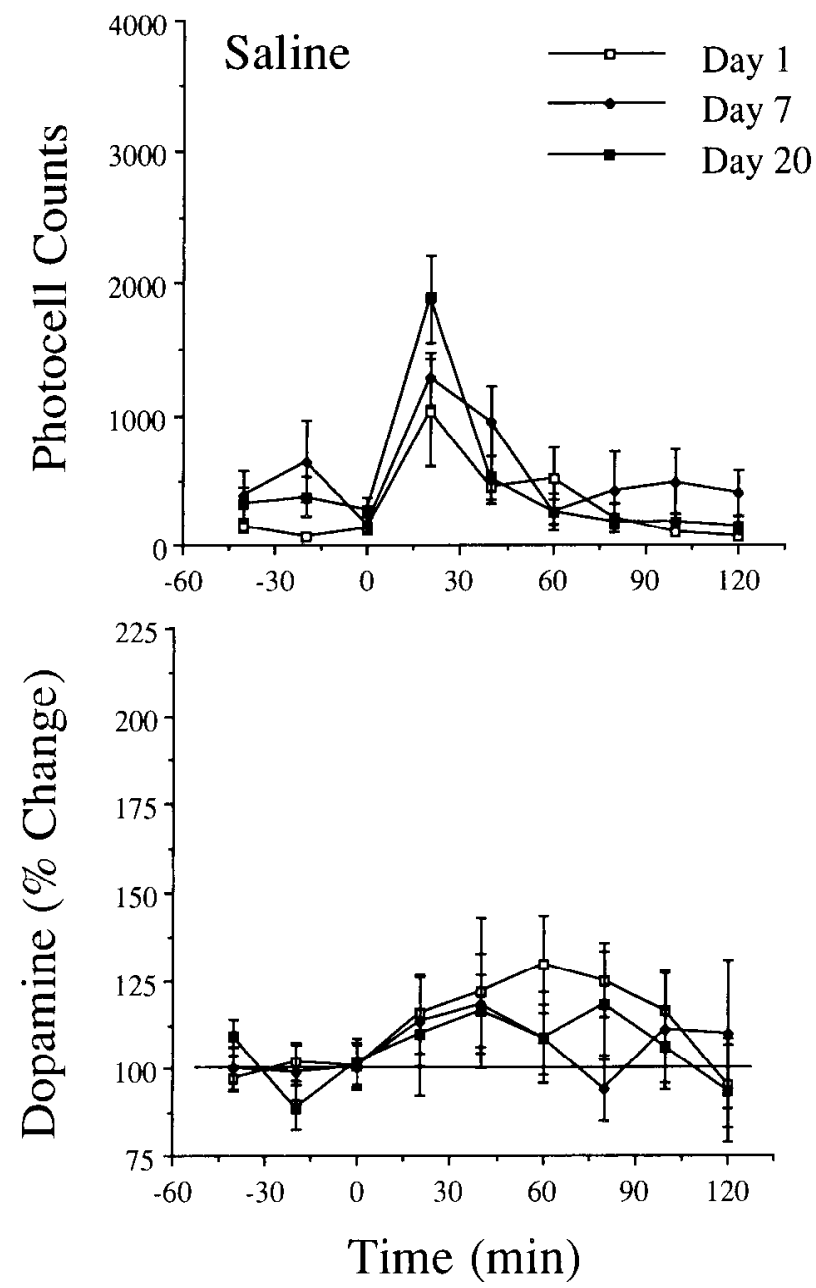

Figure 2. Effect of daily cocaine on the behavioral and neurochemical response to an acute saline challenge on day $1(\square)$, day $7(\bullet)$, or day 20 (口). These data were derived from group 1 shown in Table 1 . The neurochemical data were normalized by dividing all valucs by the average of the three baseline measurements made before the injection of acute saline. The data are shown as mean \pm SEM photocell counts or percentage change in dopamine. Basal values ( $\mathrm{fmol} / 20 \mathrm{~min}$ ) and number of determinations for each day: day $1,48 \pm 10, N=10$; day $7,79 \pm$ $19, N=11$; day $20,95 \pm 16, N=13(F=2.09, p=0.141)$. All data were analyzed using a two-way ANOVA with repeated measures over time. $F$ scores for the photocell counts: day $F=2.24, p=0.123$; time $F=15.39, p<0.001$; interaction $F=1.40, p=0.142$. Dopamine $F$ scores: day $F=0.15, p=0.866$; time $F=1.52, p=0.149$; interaction $F=0.47, p=0.961 .^{*}, p<0.05$, comparing the effect of cocaine on days 7 and 20 to the effect on day 1 within each time bin using a least significant difference post hoc analysis, as described by Milliken and Johnson (1984).

was the increase significant. The rats pretreated with the lower dose of daily cocaine ( $15 \mathrm{mg} / \mathrm{kg}$, i.p.; group 3) also showed a significant elevation in extracellular dopamine content in the first $20 \mathrm{~min}$ after cocaine injection. In contrast, rats receiving the highest dose of daily cocaine $(30 \mathrm{mg} / \mathrm{kg}$, i.p.; group 4$) \mathrm{dem}$ onstrated a significant decrease in extracellular dopamine during the first 20 min after injection.

Figure 4 shows the effect of the three daily treatment regimens on the response to a cocaine challenge $(15 \mathrm{mg} / \mathrm{kg}$, i.p.) given on days 17-21 (i.e., 11-15 d after discontinuing the daily injections). Compared to rats pretreated with daily saline (group 2), both daily cocaine pretreatment groups demonstrated behavioral sensitization. Following the lower dose of daily cocaine

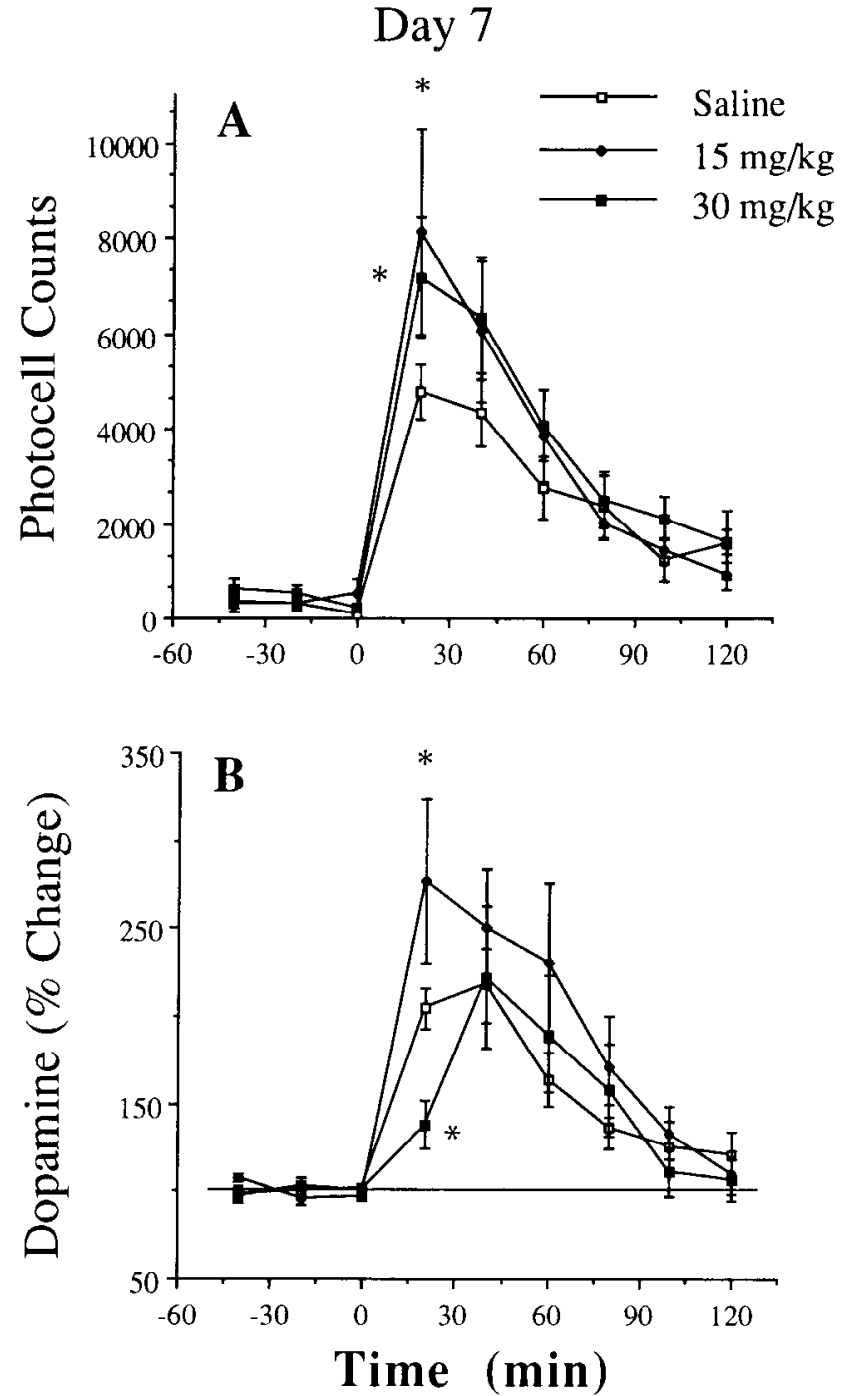

Figure 3. Effect of daily cocaine pretreatment on the effect of an acute cocaine challenge made $24 \mathrm{hr}$ after discontinuing daily treatment. Rats were pretreated with daily saline (group $2, N=9$ ), daily cocaine, (15 $\mathrm{mg} / \mathrm{kg}$; group $3, N=8$ ) or daily cocaine $(30 \mathrm{mg} / \mathrm{kg}$; group $4, N=12)$, and challenged with acute cocaine $(15 \mathrm{mg} / \mathrm{kg}$, i.p.) $1 \mathrm{~d}$ after discontinuing the daily treatments (i.e., day 7). $A$, Photocell counts are shown as mean \pm SEM. Treatment $F=1.40, p=0.26$; time $F=41.26, p<0.001$; interaction $F=1.69, p=0.051$. $B$, Extracellular dopamine is shown as the mean \pm SEM percentage change from the average of the three baseline samples. Treatment $F=1.20, p=0.32$; time $F=24.14, p<$ 0.001 ; interaction $F=1.95, p=0.017$. Basal values $(\mathrm{fmol} / 20 \mathrm{~min})$ : group $1,72 \pm 12$; group $2,77 \pm 14$; group $3,76 \pm 17(F=0.026, p$ $=0.974){ }^{*}, p<0.05$, comparing the effect of cocaine in daily cocainetreated rats (groups 3 and 4) with daily saline-treated rats (group 2) within each time bin using a least significant difference post hoc analysis as described by Milliken and Johnson (1984).

(15 mg/kg, i.p.; group 3), the increase was significant during the first 20 min after injection. In group 4 , which was pretreated with the high dose of daily cocaine $(30 \mathrm{mg} / \mathrm{kg}$, i.p.), the augmentation in photocell counts was significant at 20 and $40 \mathrm{~min}$ after injection. In comparison, the effect of daily cocaine pretreatment on extracellular dopamine was more marked. The lowest dose of daily cocaine resulted in a significant augmentation at 40,60 , and $100 \mathrm{~min}$ after the acute cocaine challenge, and in rats pretreated with the high dose of daily cocaine, extracellular dopamine was significantly augmentated at 20,40, and $60 \mathrm{~min}$ after injection. 

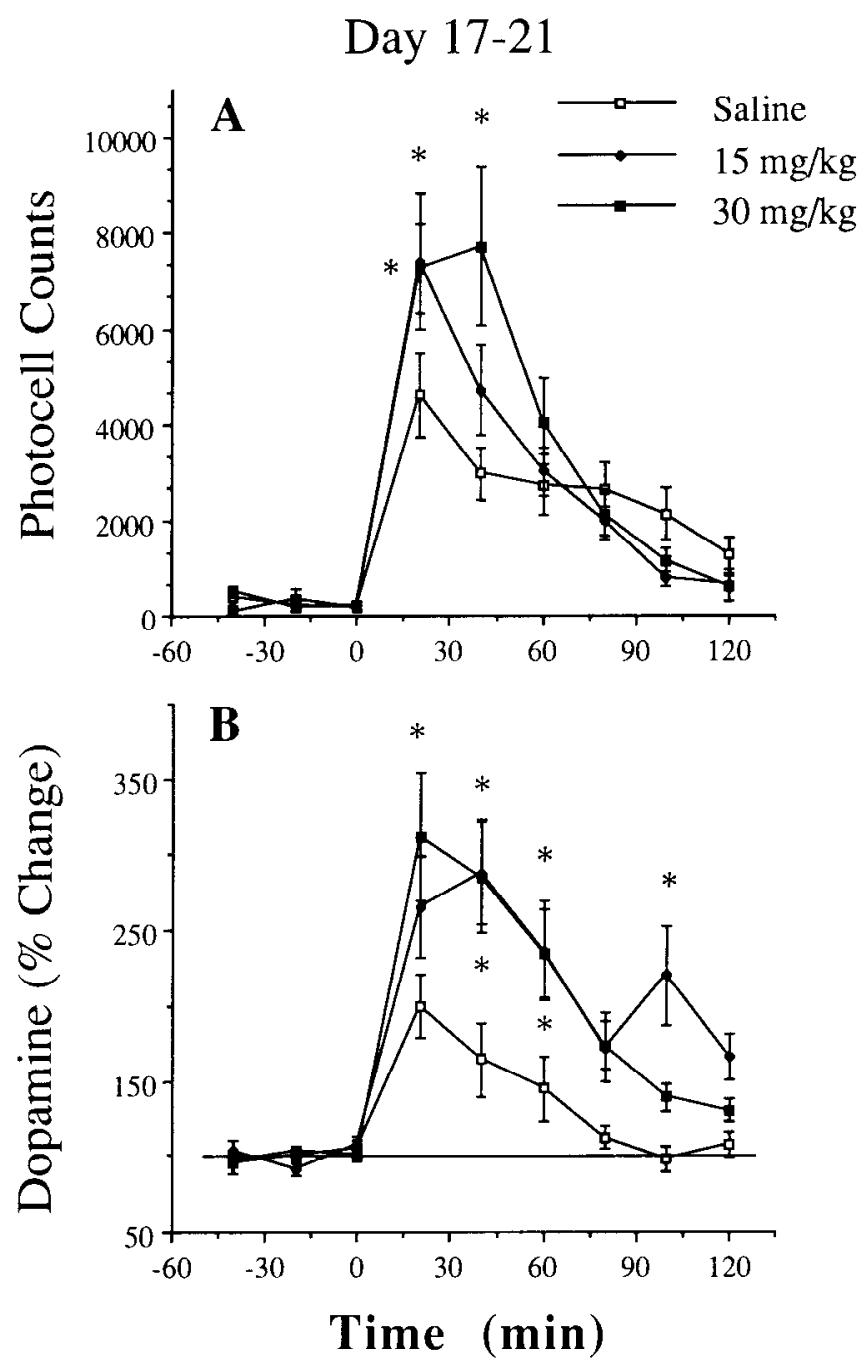

Figure 4. Effect of daily cocaine pretreatment on the effect of an acute cocaine challenge made 11-15 d after discontinuing daily treatment. Rats were pretreated with daily saline (group $2, N=8$ ), daily cocaine, $(15 \mathrm{mg} / \mathrm{kg}$; group $3, N=13)$ or daily cocaine $(30 \mathrm{mg} / \mathrm{kg}$; group $4, N=$ 9), and challenged with acute cocaine (15 mg/kg, i.p.) $11-15 \mathrm{~d}$ after discontinuing the daily treatments (i.e., days 17-21). $A$, Photocell counts are shown as mean \pm SEM. Treatment $F=1.19, p=0.32$; time $F=$ $47.31, p<0.001$; interaction $F=3.24, p<0.001$. $B$, Extracellular dopamine is shown as the mean \pm SEM percentage change from the average of the three baseline samples. Treatment $F-5.87, p-0.008$; time $F=38.06, p<0.001$; interaction $F=2.73, p<0.001$. Basal values (fmol/20 min): group 2, $67 \pm 9$; group 3,65 \pm 16 ; group 4, 62 $\pm 14(F=0.31, p=0.737) .^{*}, p<0.05$, comparing the effect of cocaine in daily cocaine-treated rats (groups 3 and 4 ) with daily saline-treated rats (group 2) within each time bin using a least significant difference post hoc analysis as described by Milliken and Johnson (1984).

Figure 5 shows the cumulative photocell counts and extracellular dopamine over $120 \mathrm{~min}$ after the injection of cocaine in groups 3 and 4 . Comparisons were made between the injection of cocaine on day 1 and the cocaine challenges made after discontinuing daily cocaine treatment (i.e., days 7, 10, 1721 , and 27-29). Daily treatment with $15 \mathrm{mg} / \mathrm{kg}$ (group 3) significantly enhanced the motor stimulant effect of cocaine at all times compared to day 1 (Fig. $5 A$ ). However, extracellular dopamine was augmented only following cocaine administration in the last two challenge periods, days 17-21 and 27-29 (Fig. $5 B$ ). After daily treatment with $30 \mathrm{mg} / \mathrm{kg}$ (group 4), photocell
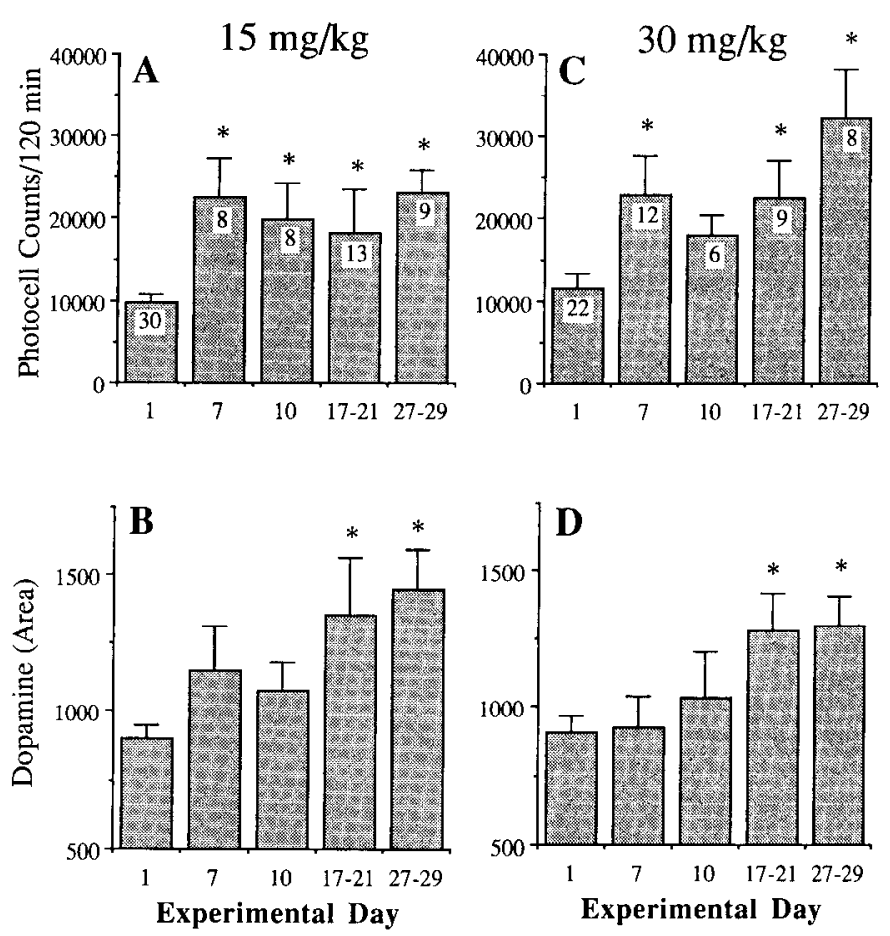

Figure 5. Cumulative photocell counts and area under the curve for extracellular dopamine during the first 120 min after injection of cocaine. Data are from groups 3 (daily $15 \mathrm{mg} / \mathrm{kg}$, i.p.) and 4 (daily $30 \mathrm{mg}$ ) $\mathrm{kg}$, i.p.). The number of determinations is shown within each bar, and the data are shown as mean \pm SEM. The dopamine values were converted to percentage change from the average of three basal values in each dialysis experiment and analyzed with a one-way ANOVA. $A$, $F(4,67)=6.93, p<0.001 . B, F(4,67)=4.64, p=0.002$. Basal values $(\mathrm{fmol} / 20 \mathrm{~min}):$ day $1,83 \pm 8$; day $7,77 \pm 14 ;$ day $10,122 \pm 38$; days $17-21,65 \pm 16$; days $27-29,43 \pm 9(F=1.97, p=0.113) . C, F(4,56)$ $=4.51, p=0.003 . D, F(4,56)=3.45, p=0.014$. Basal values (fmol/ $20 \mathrm{~min}$ ): day $1,97 \pm 14$; day $7,76 \pm 17$; day $10,55 \pm 13$; days $17-$ $21,62 \pm 14$; days $27-29,94 \pm 21(F=1.59, p=0.189){ }^{*}, p<0.05$, comparing all days to day 1 with a Dunnett's test.

counts were elevated at all times except on day 10 (Fig. 5C). Similar to the lower dose of daily cocaine, extracellular dopamine was augmented only during the last two challenge periods (Fig. 5D).

Basal concentration of dopamine, groups 5 and 6. Regression curves were obtained from the titration of increasing concentrations of dopamine through the dialysis probe. The point of no net flux is indicative of the basal concentration of extracellular dopamine. Figure 6 shows that on day 7 the basal value of dopamine was slightly, but not significantly, reduced in rats pretreated with daily cocaine compared to daily saline rats (salinc, $3.62 \pm 0.50 \mathrm{~nm}$; cocainc, $3.14 \pm 0.56 \mathrm{~nm}$ ). However, the slope of the regression line obtained from cocaine-pretreated rats was significantly elevated (saline, $0.26 \pm 0.03$; cocaine, 0.47 $\left.\pm 0.07 ; t_{10}=36.2, p<0.001\right)$. While the slopes were not significantly different on day 20 between daily saline- and cocainepretreated rats (saline, $0.31 \pm 0.08$; cocaine, $0.39 \pm 0.05$ ), the basal extracellular concentration of dopamine in cocaine-pretreated rats approached a significant increase compared to controls (saline, $3.35 \pm 0.26 \mathrm{nM}$; cocaine, $4.85 \pm 0.87 \mathrm{nM} ; t_{12}=$ $1.82, p<0.1)$. The slopes of the lines are less than those previously reported in the ventral striatum of control animals using this method (Parsons and Justice, 1991, $0.67 \pm 0.08$ and 0.64 
\pm 0.09; Parsons et al., 1991a, $0.60 \pm 0.03$; Parsons et al., 1991b, $0.60 \pm 0.03)$, because of the higher flow rate employed in the present study $(1.9 \mu \mathrm{l} / \mathrm{min}$ vs. $0.2 \mu \mathrm{l} / \mathrm{min})$. The mean correlation coefficient for each of the lines in Figure 6 was greater than 0.96 .

Histology. Figure 7 illustrates the placement of the dialysis probes in the ventral striatum from groups $1-4$. The majority of probes werc placed in the rostral nucleus accumbens, medial to the anterior commissure. While at least $50 \%$ of the dialysis membrane of most probes was in the nucleus accumbens, all probes were also located partly in the striatum and/or olfactory tubercle. Six probes in the ventral striatum were caudal to the illustrations in Figure 7 at $\mathrm{A} / \mathrm{P}=10.0 \pm 0.2 \mathrm{~mm}$. Eleven of a total of 194 probe placements from completed experiments were determined to be outside of the ventral striatum, 7 of which were rostral to the diagrams in Figure 7 . The probe placements for groups 5 and 6 were also located predominantly in the rostromedial ventral striatum. One probe placement from $31 \mathrm{com}-$ pleted experiments was rostral to the ventral striatum. In four experiments, the correlation coefficient of the regression line was $<0.90$ and these data were excluded from statistical analysis.

\section{Discussion}

The present study demonstrates that after repeated daily cocaine injections the sensitized behavioral response to an acute cocaine challenge is generally associated with an augmentation in extracellular dopamine concentrations in the ventral striatum. This is in agreement with recent studies examining this behavioral sensitization to repeated administration of cocaine (Akimoto et al., 1989; Kalivas and Duffy, 1990; Pettit et al., 1990) and other psychostimulants such as amphetamine, methamphetamine, and methylphenidate (Robinson et al., 1988; Kazahaya et al., 1989; Akimoto et al., 1990; Patrick et al., 1991). However, during the first 1-4 d after discontinuing daily treatments with the higher dose of cocaine, the behavioral augmentation was not associated with elevated extracellular dopamine. This apparent dissociation at early withdrawal time points from high doses of cocaine is consistent with the finding of Hurd et al. (1989) that $24 \mathrm{hr}$ after rats had been self-administering cocaine (approximately $30 \mathrm{mg} / \mathrm{kg}, \mathrm{i} . \mathrm{v} . \times 10 \mathrm{~d}$ ), a decrease in extracellular dopamine was produced by an acute cocaine challenge compared to a cocaine challenge in naive rats. Kuczenski and Segal (1990) and Segal and Kuczenski (1992a,b) have also observed that behavioral sensitization to repeated amphetamine or cocaine treatments was associated with a significant reduction in extracellular dopamine in both the striatum and nucleus accumbens. In these studies, moderate doses of daily amphetamine $(2.5 \mathrm{mg} / \mathrm{kg}$, i.p. $\times 6 \mathrm{~d})$ or cocaine $(10 \mathrm{mg} / \mathrm{kg}$, i.p. $\times 6 \mathrm{~d})$ were given, and the rats challenged with amphetamine or cocaine $2 \mathrm{~d}$ after discontinuing the daily treatments. In contrast, Robinson et al. (1988) observed behavioral sensitization associated with augmented dopamine release in the ventral striatum using a much more aggressive repeated amphetamine treatment regimen in which intraperitoneal doses of amphetamine were escalated from 1.0 to $10.0 \mathrm{mg} / \mathrm{kg}$ over a $35 \mathrm{~d}$ treatment period. However, the test for sensitization was not made until 15-21 d after discontinuing the sensitizing treatment regimen.

The data to date with daily cocaine and amphetamine indicate that tolerance may develop to psychostimulant-induced elevation in extracellular dopamine that persists for a few days after discontinuing administration. Thus, Hurd et al. (1989) and Segal and Kuczenski (1992a,b) observed a decrease in the ca-

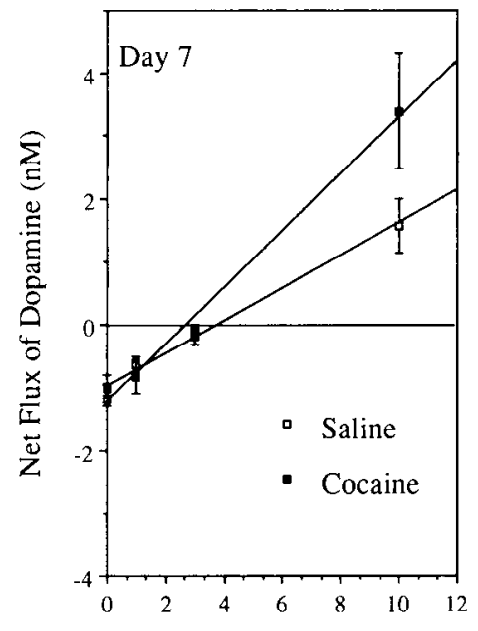

Dopamine in Perfusate (nM)

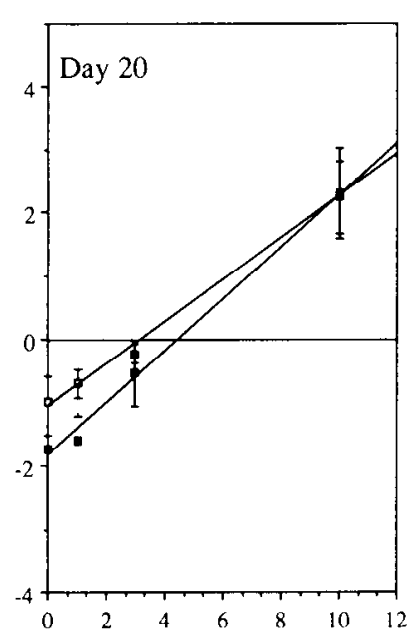

Dopamine in Perfusate (nM)
Figure 6. Basal extracellular concentration of dopamine in ventral striatum determined using in vivo net flux of dopamine. Dialysis was performed on day 7 or day 20 after the rats had been pretreated with saline (group 5 in Table 1) or cocaine (group 6) on days 1-6. Each line was derived from six to eight animals, and the data are shown as the mean \pm SEM difference between the concentration of dopamine applied to the dialysis probe in the perfusate and that collected at the probe effluent (Parsons and Justice, 1991). Zero on the $y$-axis is the interpolated concentration of dopamine in the perfusate at which no net flux with the extracellular fluid occurs and corresponds to the basal concentration of dopamine. The basal concentration of dopamine was unaltered in cocaine-pretreated rats at either withdrawal time, but on day 7 the slope of the line was significantly elevated.

pacity of an acute challenge with cocaine or amphetamine to elevate extracellular dopamine during the early withdrawal from a daily drug treatment regimen. Likewise, we found a reduction in the effect of cocaine on day 7 in rats pretreated daily with 30 $\mathrm{mg} / \mathrm{kg}$ intraperitoneal cocaine (group 4), but also observed that the apparent tolerance subsided with time such that an augmentation in extracellular dopamine was manifest by $11-15 \mathrm{~d}$ following the discontinuation of daily cocaine. One study reported a similar increase in the sensitization of in vitro dopamine release with the passage of time after discontinuing a sensitizing psychostimulant treatment regimen (Kolta et al., 1985). Also, many studies have revealed an increase in behavioral sensitization over time (Hitzemann et al., 1980; Hirabayashi and Alam, 1981; Kolta et al., 1985; Antelman, 1988; Kalivas and Duffy, 1989; Robinson, 1991).

There are a number of possible mechanisms for the development of short-term tolerance to the effects of cocaine on extracellular dopamine. First, it has been proposed that, similar to high doses of amphetamines (Seiden et al., 1988), repeated cocaine administration may reduce the concentration of dopamine in various terminal fields (Dackis and Gold, 1985). In general, the measurement of tissue levels of dopamine in numerous laboratories has failed to verify this hypothesis (Kalivas et al., 1988; Kleven et al., 1988; Yeh and De Souza, 1991; but see Karoum et al., 1990). Likewise, there is not a reduction in basal levels of extracellular dopamine in the early withdrawal period after repeated cocaine or amphetamine (Robinson et al., 1988; Kalivas and Duffy, 1990; Parsons et al., 1991; Segal and Kuczenski, 1992a,b; present results). However, there have been reports of diminished levels of dopamine synthesis and tyrosine hydroxylase phosphorylation in the nucleus accumbens after 
Figure 7. Illustration of dialysis probe placement in the ventral striatum, including the nucleus accumbens, olfactory tubercle, and striatum. Although the active portion of the probe varied from 2.0 to $3.0 \mathrm{~mm}$ in length, all probes were drawn as $2.5 \mathrm{~mm}$. The broken track lines refer to probe placements excluded from data analysis. An additional seven were located rostral to the illustration. The number on each section refers to millimeters rostral to the interaural line according to the atlas of Paxinos and Watson (1986).

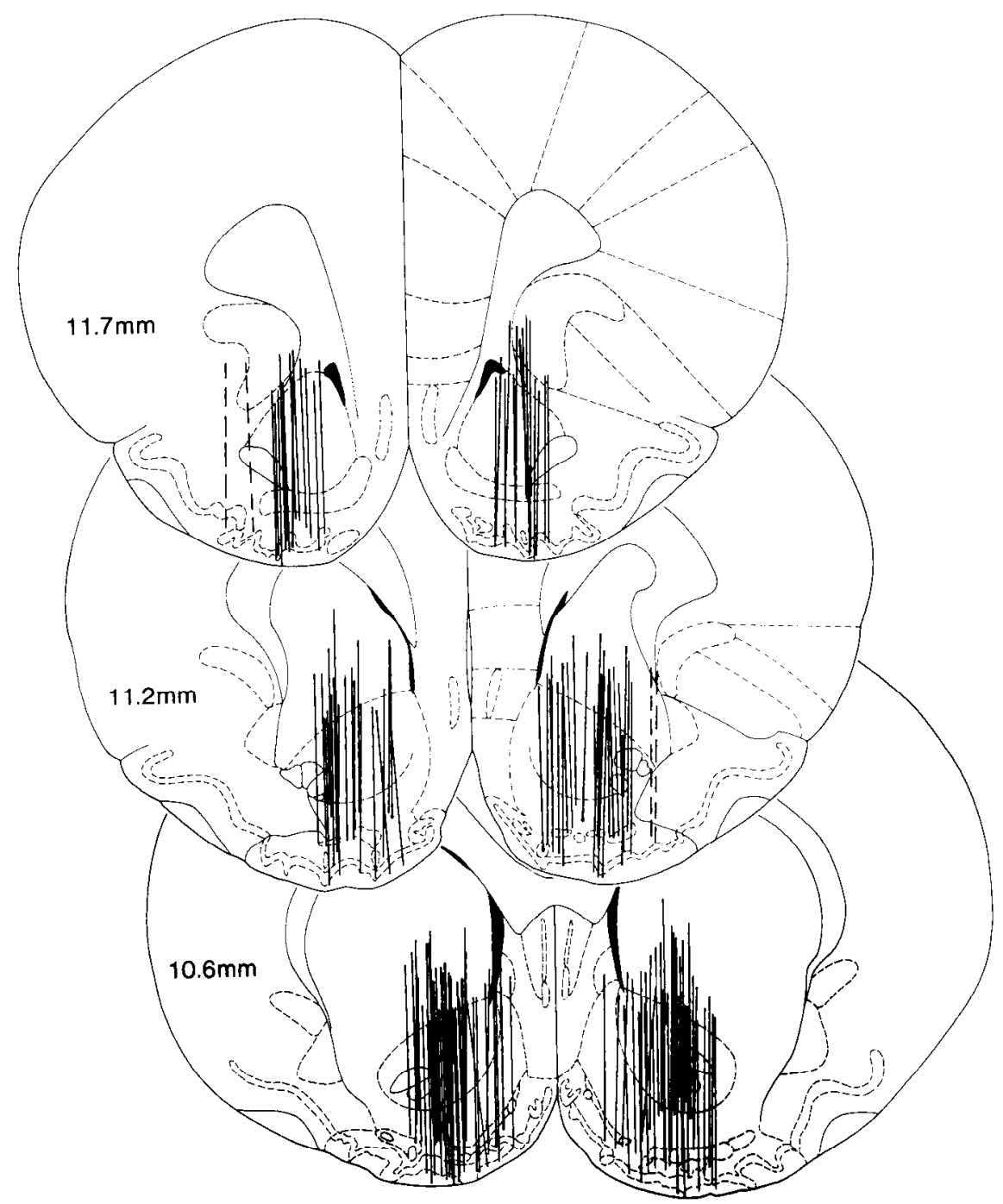

concentrations of dopamine in the synaptic cleft. However, $\mathrm{Ng}$ et al. (1991) demonstrated in rats pretreated with daily cocaine that electrical stimulation of the medial forebrain bundle significantly augmented dopamine overflow compared to control rats, even in the presence of the enhanced dopamine uptake. Furthermore, similar to the present report, this group found that after $24 \mathrm{hr}$ of withdrawal from repeated cocaine, the basal levels of extracellular dopamine were unchanged in the presence of increased dopamine uptake (Parsons et al., 1991). Thus, enhanced reuptake does not offer a complete explanation for the lack of an augmentation in synaptic dopamine levels during the early withdrawal period from daily cocaine.

A final explanation for the apparent tolerance is that there may be an alteration in the presynaptic regulation of dopamine release. Likely candidates include changes in presynaptic inhibition produced by $\mathrm{D}_{2}$ autoreceptors or changes in the presynaptic stimulation of dopamine release by excitatory amino acids or 5-HT. Data suggesting an alteration in $\mathrm{D}_{2}$ autoreceptor function following repeated cocaine administration have been inconsistent (Dwoskin et al., 1988; Peris et al., 1990; Yi and Johnson, 1990). Supporting a role for excitatory amino acids is the observation that systemic administration of the noncompetitive NMDA receptor antagonist MK-801 with cocaine prevents the development of behavioral sensitization (Karler et al., pamine, presumably resulting from augmented reuptake, may partly mask the appearance at the dialysis probe of increased 
1989). Also, lesions of the fimbria, which would disrupt the excitatory amino acid projection from the hippocampus to the nucleus accumbens, prevent the development of behavioral sensitization to cocaine (Yoshikawa et al., 1991). A role for 5-HT is indicated by the fact that cocaine augments 5 -HT transmission by binding the 5-HT uptake carrier (Reith et al., 1986), and the recent observation that the in vivo administration of 5-HT into the nucleus accumbens increases the extracellular level of accumbal dopamine (Benloucif and Galloway, 1991; Chen et al., 1991).

Regardless of the mechanism mediating the lack of augmented extracellular dopamine during the early withdrawal period, it remains unknown how behavioral sensitization could occur in the absence of enhanced dopamine transmission in the nucleus accumbens. A number of factors may be involved. First, behavioral sensitization may be mediated by nondopaminergic substrates or dopamine terminals outside the ventral striatum. 5-HT augments dopamine release (Imperato and Angelucci, 1989; Jiang et al., 1990; Benloucif and Galloway, 1991; Chen et al., 1991; Yi et al., 1991), and a role for 5-HT and norepinephrine in modulating the acute motor effect of psychostimulants has been described (Segal, 1976; Dickinson et al., 1988; Kuczenski and Segal, 1988; Taghzouti et al., 1988). Also, sensitization of adrenergic transmission in the hippocampus can be produced by prior exposure to chronic stress (Nisenbaum et al., 1991). Although the striatum, nucleus accumbens, and olfactory tubercles are the dopamine terminal fields most frequently associated with the modulation of motor activity by amphetamine-like psychostimulants, other dopamine terminal fields may be important. Notably, pharmacologically stimulated dopamine transmission in the ventral pallidum (Napier et al., 1988; Klitenick et al., in press) and prefrontal cortex (Louilot et al., 1989) has been shown to modulate locomotor activity and/or dopamine release in the nucleus accumbens. While enhanced dopamine transmission in the ventral pallidum increases motor activity, dopamine appears to have an inhibitory influence in the prefrontal cortex (Deutch and Roth, 1990). Thus, although acute cocaine injection increases the extracellular content of dopamine in the prefrontal cortex (Moghaddam and Bunney, 1989), perhaps behavioral sensitization could be associated with a decrease in extracellular dopamine in the prefrontal cortex (Sorg, in press).

A second explanation for the apparent lack of an association between extracellular dopamine and behavioral sensitization may be the presence of environmental conditioning previously identified with single and repeated administration of psychostimulants (Tilson and Rech, 1973; Post et al., 1981; Weiss et al., 1989; see Stewart and Vezina, 1988, for review). Furthermore, Beninger et al. $(1983,1986)$ found that amphetamineand cocaine-conditioned locomotor behavior does not depend on intact dopamine transmission. Although in the present study the majority of cocaine injections were made in the home cage, all rats showing behavioral sensitization received a single, potentially conditioning exposure to cocaine in the dialysis chamber on day 1 prior to the cocaine challenge during the withdrawal period. Also, the rats could have become conditioned to the injection procedure or interoceptive cues, such as local anesthesia at the injection site, regardless of the environment where cocaine was administered (see Stewart and Vezina, 1988, 1991, for discussion of these issues).

A final possible explanation is that the postsynaptic response to dopamine has been augmented such that the same or less dopamine release could elicit a greater behavioral stimulant response. This possibility is consistent with reports showing that the inhibitory effect of dopamine on the firing frequency of neurons in the striatum (Rebec and Groves, 1976) and nucleus accumbens (Henry et al., 1989) is enhanced in rats pretreated with repeated injections of cocaine or amphetamine (but see Kamata and Rebec, 1985). The augmented response to iontophoretic dopamine in the nucleus accumbens of rats pretreated with repeated cocaine injections appears to result from an enhanced responsiveness of the $D_{1}$ receptor and endures for up to $30 \mathrm{~d}$ after discontinuing the repeated cocaine treatments (Henry and White, 1991). This is consistent with reports showing that an augmentation in dopamine stimulated adenylyl cyclase in the striatum of rats pretreated with daily amphetamine (Roseboom et al., 1990; Beitner-Johnson et al., in press; but see Barnett et al., 1987). In addition, the density of $D_{2}$ receptors is upregulated in the nucleus accumbens during the early withdrawal period after daily treatment with cocaine (Goeders and Kuhar, 1987; Kleven et al., 1990; Peris et al., 1990; Zeigler et al., in press).

Parsons et al. (1991a) examined the effect of repeated cocaine $(20 \mathrm{mg} / \mathrm{kg}$, i.p. $\times 10 \mathrm{~d})$ on basal dopamine levels using the in vivo dopamine flux method and found that at $10 \mathrm{~d}$ of withdrawal, extracellular dopamine in the nucleus accumbens was reduced. In contrast, we observed no change $14 \mathrm{~d}$ after discontinuing repeated cocaine treatments (group 6). An explanation for this discrepancy is not readily apparent, but may involve differences in treatment and withdrawal parameters. Also, differences in dialysis buffer and flow rate may affect the basal levels of extracellular dopamine. Notably, the higher flow rate employed in the present study $(1.9 \mu \mathrm{l} / \mathrm{min}$ vs. $0.2 \mu \mathrm{l} / \mathrm{min})$ may cause a modest depletion of extracellular dopamine, as reflected by the lower basal levels of dopamine in the present study (3.35-3.62 nм) versus those obtained by Justice and coworkers (Parsons and Justice, 1991, 3.8-4.5 nм; Parsons et al., 1991, $3.9 \mathrm{~nm}$; Parsons et al., 1991b, $6.9 \mathrm{~nm}$ ). It is possible that a modest depletion may have masked the reduction in daily cocainepretreated rats.

In conclusion, long-term behavioral sensitization to repeated cocaine administration was associated with an augmentation in extracellular dopamine content in the ventral striatum. However, behavioral sensitization was present in the absence of augmented dopamine levels during the early withdrawal period from a relatively high-dosage, repeated cocaine pretreatment regimen. Thus, while alterations in dopamine release in the ventral striatum are likely to contribute to the long-term expression of behavioral sensitization produced by repeated cocaine administration, other factors need to be considered during the early withdrawal period.

\section{References}

Akimoto K, Ilamamura T, Otsuki S (1989) Subchronic cocaine treatment enhances cocaine-induced dopamine efflux, studies by in vivo intracerebral dialysis. Brain Res 490:339-344.

Akimoto K, Hamamura T, Kazahaya Y, Akiyama K, Otsuki S (1990) Enhanced extracellular dopamine level may be the fundamental neuropharmacological basis of cross-behavioral sensitization between methamphetamine and cocaine-an in vivo dialysis study in freely moving rats. Brain Res 507:344-346.

Antelman SM (1988) Stressor-induced sensitization to subsequent stress: implications for the development and treatment of clinical disorders. In: Sensitization in the nervous system (Kalivas PW, Barnes CD, eds), pp 227-256. Caldwell, NJ: Telford. 
Barnett JA, Segal DS, Kuczenski R (1987) Repeated amphetamine pretreatment alters the responsiveness of striatal dopamine-stimulated adenylate cyclase to amphetamine-induced desensitization. $\mathbf{J}$ Pharmacol Exp Ther 242:40-47.

Beitner-Johnson D, Nestler EJ (1991) Morphine and cocaine exert common chronic actions on tyrosine hydroxylase in dopaminergic brain reward regions. J Neurochem 57:344-347.

Beitner-Johnson D, Guitart X, Nestler EJ (1992) Common intracellular actions of chronic morphine and cocaine in dopaminergic brain reward regions. Ann NY Acad Sci 654:70-87.

Beninger RJ, Hahn BL (1983) Pimozide blocks establishment but not expression of amphetamine-produced environment-specific conditioning. Science 220:1304.

Beninger RJ, Herz RS (1986) Pimozide blocks establishment but not expression of cocaine-produced environment-specific conditioning. Life Sci 38:1425.

Benloucif S, Galloway MP (1991) Facilitation of dopamine release in vivo by serotonin agonists: studies with microdialysis. Eur J Pharmacol 200:1-8.

Brock JW, Ng JP, Justice JB Jr (1990) Effect of chronic cocaine on dopamine synthesis in the nucleus accumbens as determined by microdialysis perfusion with NSD-1015. Neurosci Lett 1 17:234-239.

Chen J, van Praag HM, Gardner EL (1991) Activation 5-HT 3 receptor by 1 -phenylbiguanide increases dopamine release in the rat nucleus accumbens. Brain Res 543:354-357.

Dackis CA, Gold MS (1985) New concepts in cocaine addiction: the dopamine depletion hypothesis. Neurosci Biobehav Rev 9:469-482.

Delfs JM, Schreiber I, Kelley AE (1990) Microinjection of cocaine into the nucleus accumbens elicits lotomotor activation in the rat. $\mathrm{J}$ Neurosci 10:303-310.

Deutch AY, Roth RH (1990) The determinants of stress-induced activation of the prefrontal cortical dopamine system. Prog Brain Res 85:357-393.

Di Chiara G, Imperato A (1988) Drugs abused by humans preferentially increase synaptic dopamine concentrations in the mesolimbic system of freely moving rats. Proc Natl Acad Sci USA 85:5274-5278.

Dickinson SL, Gadie B, Tullock IF (1988) Alpha ${ }_{1}$ and Alpha ${ }_{2}$-adrenoreceptor antagonists differentially influence locomotor and stereotyped behavior induced by $d$-amphetamine and apomorphine in the rat. Psychopharmacology 96:521-527.

Downs AW, Eddy NB (1932) The effect of repeated doses of cocaine on the rat. J Pharmacol Exp Ther 46:199-202.

Dwoskin LP, Peris J, Yasuda RP, Philpott K, Zahniser NR (1988) Repeated cocaine administration results in supersensitivity of striatal D-2 dopamine autoreceptors to pergolide. Life Sci 42:255-262.

Goeders NE, Kuhar MJ (1987) Chronic cocaine administration induces opposite changes in dopamine receptors in the striatum and nucleus accumbens. Alcohol Drug Res 7:207-216.

Hadfield MG, Nuggent EA (1983) Cocaine: comparative effect on dopamine uptake in extrapyramidal and limbic systems. Biochem Pharmacol 32:744-746.

Hanson GR, Matsuda LA, Gibb JW (1987) Effects of cocaine on methamphetamine-induced neurochemical changes: characterization of cocaine as a monoamine uptake blocker. J Pharmacol Exp Ther 242:507-513.

Henry DJ, White FJ (1991) Repeated cocaine administration causes persistent enhancement of D1 dopamine receptor sensitivity within the rat nucleus accumbens. J Pharmacol Exp Ther 258:882-890.

Henry DJ, Margaret AG, White FJ (1989) Electrophysiological effects of cocaine in the mesoaccumbens dopamine system: repeated administration. J Pharmacol Exp Ther 251:833-839.

Hirabayashi M, Alam MR (1981) Enhancing effect of methamphetamine on ambulatory activity produced by repeated administration in mice. Pharmacol Biochem Behav 15:925-932.

Hitzemann K, Wu J, Hom D, Loh H (1980) Brain locations controlling the behavioral effects of chronic amphetamine intoxication. Psychopharmacology 72:93-101.

Hurd YL, Weiss F, Koob GF, Ungerstedt N-EU (1989) Cocaine reinforcement and extracellular dopamine overflow in rat nucleus accumbens: an in vivo microdialysis study. Brain Res 498:199-203.

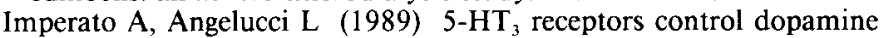
release in the nucleus accumbens of freely moving rats. Neurosci Lett 101:214-217.

Izenwasser S, Cox BM (1990) Daily cocaine treatment produces a persistent reduction of $\left[{ }^{3} \mathrm{H}\right]$ dopamine uptake in vitro in rat nucleus accumbens but not striatum. Brain Res 531:338-341.
Izenwasser S, Werling LL, Cox BM (1990) Comparison of the effects of cocaine and other inhibitors of dopamine uptake in rat striatum, nucleus accumbens, olfactory tubercle, and medial prefrontal cortex. Brain Res 520:303-309.

Jiang LH, Ashby CR Jr, Kasser RJ, Wang RY (1990) The effect of intraventricular administration of the $5-\mathrm{HT}_{3}$ receptor agonist 2 -methylserotonin on the release of dopamine in the nucleus accumbens: an in vivo chronocoulometric study. Brain Res 513:156-160.

Kalivas PW, Duffy P (1989) Similar effects of daily cocaine and stress on mesocorticolimbic dopamine neurotransmission in the rat. Biol Psychiatry 25:913-928.

Kalivas PW, Duffy P (1990) The effect of acute and daily cocaine treatment on extracellular dopamine in the nucleus accumbens. Synapse 5:48-58.

Kalivas PW, Stewart J (1991) Dopamine transmission in drug- and stress-induced behavioral sensitization. Brain Res Rev 16:223-244.

Kalivas PW, Duffy P, DuMars LA, Skinner C (1988) Neurochemical and behavioral effects of acute and daily cocaine. J Pharmacol Exp Ther 245:485-492.

Kamata K, Rebec GV (1985) Iontophoretic evidence for subsensitivity of postsynaptic dopamine receptors following long-term amphetamine administration. Eur J Pharmacol 106:393-397.

Karler R, Calder LD, Chaudhry IA, Turkanis SA (1989) Blockade of 'reverse tolerance' to cocaine and amphetamine by MK-801. Life Sci 45:599-606.

Karoum F, Suddath RL, Wyatt RJ (1990) Chronic cocaine and rat brain catecholamines: long-term reduction in hypothalamic and frontal cortex dopamine metabolism. Eur J Pharmacol 186:1-8.

Kazahaya Y, Akimoto K, Saburo O (1989) Subchronic methamphetamine treatment enhances methamphetamine- or cocaine-induced dopamine efflux in vivo. Biol Psychiatry 25:903-912.

Kelley PH, Iversen SD (1975) Selective 6-OHDA-induced destruction of mesolimbic dopamine neurons: abolition of psychostimulant-induced locomotor activity in rats. Eur J Pharmacol 40:45-56.

Kleven MS, Woolverton WL, Seiden LS (1988) Lack of long-term monoamine depletions following repeated or continuous exposure to cocaine. Brain Res Bull 21:233-237.

Kleven MS, Perry B, Woolverton WL, Seiden LS (1990) Effects of repeated injection of cocaine on D1 and D2 receptors in rat brain. Brain Res 532:265-279.

Klitenick MA, Deutch AY, Churchill L, Kalivas PW (in press) Topography and functional role of dopaminergic projections from the ventral mesencephalic tegmentum to the ventral pallidum. Neuroscience, in press.

Kolta MG, Shreve P, De Suuza V, Uretsky NJ (1985) Time course of the development of the enhanced behavioral and biochemical responses to amphetamine after pretreatment with amphetamine. Neuropharmacology 24:823-829.

Kuczenski R, Segal DS (1988) Psychomotor stimulant-induced sensitization: behavioral and neurochemical correlates. In: Sensitization in the nervous system (Kalivas PW, Barnes CD, eds), pp 175-205. Caldwell, NJ: Telford.

Kuczenski R, Segal DS (1990) In vivo measures of monoamines during amphetamine-induced behavior in rat. Prog Neuropsychopharmacol Biol Psychiatry 14:S37-S50.

Lonroth P, Janson PA, Smith U (1987) A microdialysis method allowing characterization of intercellular water space in humans. Am J Physiol 253:E228-E231.

Louilot A, Le Moal M, Simon H (1989) Opposite influences of dopaminergic pathways to the prefrontal cortex or the septum on the dopaminergic transmission in the nucleus accumbens. An in vivo voltammetric study. Neuroscience 29:45-56.

Milliken GA, Johnson DE (1984) Analysis of messy data, Vol I, Designed experiments. Belmont, CA: Lifetime Learning.

Moghaddam B, Bunney BS (1989) Differential effect of cocaine on extracellular dopamine levels in rat medial prefrontal cortex and nucleus accumbens: comparison to amphetamine. Synapse 4:156-161.

Napier TC, An D, Austin MC, Kalivas PW (1988) Opiates microinjected into the ventral pallidum/substantia innominata (VP/SI) produce locomotor responses that involve dopaminergic systems. Soc Neurosci Abstr 14:293.

Ng JP, Hubert GW, Justice JB Jr (1991) Increased stimulated release and uptake of dopamine in nucleus accumbens after repeated cocaine administration as measured by in vivo voltammetry. J Neurochem $56: 1485-1492$. 
Nisenbaum LK, Zigmond MJ, Sved AF, Abercrombie ED (1991) Prior exposure to chronic stress results in enhanced synthesis and release of hippocampal norepincphrinc in response to a novel stressor. J Neurosci 11:1478-1484.

Parsons LH, Justice JB Jr (1991) Quantitative neurotransmitter microdialysis: extracellular dopamine in the nucleus accumbens. J Neurochem 58:212-218.

Parsons LH, Smith AD, Justice JB Jr (1991a) Basal extracellular dopamine is decreased in the rat nucleus accumbens during abstinence from chronic cocaine. Synapse 9:60-65.

Parsons LH, Smith AD, Justice JB Jr (199 l b) The in vivo microdialysis recovery of dopamine is altered independently of basal level by 6hydroxydopamine lesions to the nucleus accumbens. J Neurosci Methods 40:139-147.

Patrick SL, Thompson TL, Walker JM, Patrick RL (1991) Concomitant sensitization of amphetamine-induced behavioral stimulation and in vivo dopamine relcase from rat caudate nucleus. Brain Res 538:343-346.

Paxinos G, Watson C (1986) The rat brain in stereotaxic coordinates. 2d ed. New York: Academic.

Pellegrino LK, Pellegrino AS, Cushman AJ (1979) A stereotaxic atlas of the rat brain. New York: Plenum.

Peris J, Boyson SJ, Cass WA, Curella P, Dwoskin LP, Larson G, Lin L-H, Yasuda RP, Zahniser NR (1990) Persistence of neurochemical changes in dopamine systems after repeated cocaine administration. J Pharmacol Exp Ther 253:38-44.

Pettit HO, Pan H-T, Parsons LH, Justice JB Jr (1990) Extracellular concentrations of cocaine and dopamine are enhanced during chronic cocaine administration. J Neurochem 55:798-804.

Post RM, Rose H (1976) Increasing effects of repetitive cocaine administration in the rat. Nature 260:731-732.

Post RM, Lockfeld A, Squillace KM, Contel NR (1981) Drug environment interaction: context dependency of cocaine induced behavioral sensitization. Life Sci 28:755-760.

Rebec GV, Groves PM (1976) Enhancement of effects of dopaminergic agonists on neuronal activity in the caudate-putamen of the rat following long-term $d$-amphetamine administration. Pharmacol Biochem Behav 5:349-357.

Reith MEA, Meisler BE, Sershen H, Laitha A (1986) Structural requirements for cocaine congeners to interact with dopamine and serotonin uptake sites in mouse brain and to induce stereotyped behavior. Biochem Pharmacol 35:1123-1129.

Robinson TE (1991) The neurobiology of amphetamine psychosis: evidence from studies with an animal model. In: Taniguchi symposia on brain sciences, Vol 14, Biological basis of schizophrenic disorders (Nakazawa T, ed), pp 185-201. Tokyo: Japan Scientific Societies.

Robinson TE, Becker JB (1986) Enduring changes in brain and behavior produced by chronic amphetamine administration: a review and evaluation of animal models of amphetamine psychosis. Brain Res Rev 11:157-198.

Robinson TE, Whishaw IQ (1988) Normalization of extracellular dopamine in striatum following recovery from a partial unilateral 6-OHDA lesion of the substantia nigra: a microdialysis study in freely moving rats. Brain Res 450:209-224.

Robinson TE, Jurson PA, Bennett JA, Bentgen KM (1988) Persistent sensitization of dopamine neurotransmission in ventral striatum (nucleus accumbens) produced by prior experience with $(+)$-amphetamine: a microdialysis study in freely moving rats. Brain Res 462 : 211-222.

Roseboom PH, Keiklani Hewlett GH, Gnegy ME (1990) Repeated amphetamine administration alters the interaction between $D_{1}$-stim- ulated adenylyl cyclase activity and calmodulin in rat striatum. J Pharmacol Exp Ther 255:197-203.

Scheel-Kruger J, Graestrup C, Nielson M, Golembiowski K, Mogilmicka $E$ (1977) Cocaine: discussion on the role of dopamine in the biochemical mechanism of action. In: Cocaine and other stimulants (Ellinwood E Jr, Kilby M, eds), pp 373-407. New York: Plenum.

Segal DS (1976) Differential effects of para-chlorophenylalanine on amphetamine-induced locomotion and stereotypy. Brain Res 116 267-276.

Segal DS, Kuczenski R (1992a) In vivo microdialysis reveals a diminished amphetamine-induced dopamine response corresponding to behavioral sensitization produced by repeated amphetamine pretreatment. Brain Res 571:330-337.

Segal DS, Kuczenski R (1992b) Repeated cocaine administration induces behavioral sensitization and corresponding decreased extracellular dopamine responses in caudate and accumbens. Brain Res 577:351-355.

Seiden LS, Commins DL, Vosmer G, Axt K, Marek G (1988) Neurotoxicity in dopamine and 5-hydroxytryptamine terminal fields: a regional analysis in nigrostriatal and mesolimbic projections. Ann NY Acad Sci 537:161-172.

Sorg B (1992) Mesocorticolimbic dopamine systems: cross-sensitization between stress and cocaine. Ann NY Acad Sci 654:136-144.

Stewart J, Vezina P (1988) Conditioning and behavioral sensitization. In: Sensitization in the nervous system (Kalivas PW, Barnes CD, eds), pp 207-224. Caldwell, NJ: Telford.

Stewart J, Vezina P (1991) Extinction training abolishes conditioned stimulus control but spares sensitized responding to amphetamine. Behav Pharmacol 2:65-71.

Taghzouti K, Simon H, Herve D, Blanc G, Studler JM, Glowinskin J, LeMoal M, Tassin JP (1988) Bchavioral deficits induced by an electrolytic lesion of the rat ventral mesencephalic tegmentum are corrected by a superimposed lesion of the dorsal noradrenergic system. Brain Res 440:172-176.

Taylor D, Ho BT (1977) Neurochemical effects of cocaine following acute and repeated injection. J Neurosci Res 3:95-101.

Tilson HA, Rech RH (1973) Conditioned drug effects and absence of tolerance to $d$-amphetamine induced motor activity. Pharmacol Biochem Behav 1:149-153.

van Rossum J, Van Schoot J, Hurkman J (1962) Mechanism of action of cocaine and amphetamine in the brain. Experientia 18:229-230.

Weiss SRB, Post RM, Pert A, Woodward R, Murman D (1989) Context-dependent cocaine sensitization: differential effect of haloperidol on development versus expression. Pharmacol Biochem Behav 34: 655-661.

Yeh SY, De Souza EB (1991) Lack of neurochemical evidence for neurotoxic effects of repeated cocaine administration in rats on brain monoamine neurons. Drug Alcohol Depend 27:51-61.

Yi S-J, Johnson KM (1990) Effects of acute and chronic administration of cocaine on striatal dopamine uptake, compartmentalization and release of $\left[{ }^{3} \mathrm{H}\right]$ dopamine. Neuropharmacology 29:475-486.

Yi S-J, Gifford AN, Johnson KM (1991) Effect of cocaine and 5-HT, receptor antagonists on 5-HT-induced $\left[{ }^{3} \mathrm{H}\right]$ dopamine release from rat striatal synaptosomes. Eur J Pharmacol 199:185-189.

Yoshikawa T, Shibuya H, Kaneno S, Toru M (1991) Blockade of behavioral sensitization to methamphetamine by lesion of hippocampo-accumbal pathway. Life Sci 48:1325-1332.

Zeigler S, Lipton J, Toga A, Ellison G (1991) Continuous cocaine administration produces persisting changes in brain neurochemistry and behavior. Brain Res 552:27-35. 